\title{
PERFIL DOS PROFISSIONAIS CONTÁBEIS DOS ESCRITÓRIOS DE CONTABILIDADE QUE RECEBERAM O PREMMIO DESTAQUE EMPRESARIAL NA CIDADE TANGARÁ DA SERRA - MT
}

\author{
Jucélia Canachiro de Oliveira ${ }^{1}$ \\ Josiane Silva Costa dos Santos Costa ${ }^{2}$
}

\section{RESUMO}

Esta pesquisa teve como objetivo identificar o perfil dos profissionais contábeis dos escritórios de contabilidade que receberam o prêmio destaque empresarial na cidade de Tangará da Serra - MT. Trata-se de uma pesquisa de natureza exploratória e descritiva com abordagem quantitativa. Os instrumentos de coleta foram questionários fechados aplicados no período de 07 a 18 de maio de 2012. Compuseram a amostra 86 profissionais distribuídos em 15 escritórios de contabilidade. Os resultados indicaram que $41 \%$ dos profissionais possuem curso superior completo em contabilidade e $59 \%$ estão cursando. O principal motivo pela escolha da profissão foi o ótimo mercado de trabalho e como dificuldade as constantes alterações na legislação. Destaca que do total dos entrevistados as mulheres foram a maioria, indicado que existe uma mudança de perfil desses profissionais já que até pouco tempo era predominantemente masculino.

Palavras-chaves: Perfil do Profissional Contábil, Contabilidade, Mercado de Trabalho.

\section{INTRODUÇÃO}

Os profissionais da contabilidade vivem em uma sociedade onde as regras econômicas, políticas e fiscais são constantemente mudadas. E com a atual globalização da economia, o contador não deve se limitar somente às áreas de aspectos legais e fiscais, mas visar os aspectos gerenciais, e outros assuntos econômicos que influenciam a atuação da profissão contábil. (AVI,1999)

$\mathrm{O}$ bom profissional procura adequar-se às situações futuras, pois se sabe que o mercado de trabalho esta cada vez mais exigente, na qualidade, atendimento e eficiência. É essencial que o profissional contábil, rapidamente se adéqüe às novas circunstâncias.(AVI,1999) Segundo Silva (2000, p26) o mercado atual requer modernidade, criatividade, novas tecnologias, novos conhecimentos e mudanças urgentes, impondo, com isso um desafio: o de continuar competindo.(SILVA, 2000)

A Associação Comercial e Empresarial de Tangará da Serra (ACITS), é uma entidade sem fins lucrativos e tem como missão principal unir os setores empresariais.

\footnotetext{
${ }^{1}$ Acadêmica do curso de Ciências Contábeis da UNEMAT - Campus de Tangará da Serra, e-mail: juceliakanachiro@hotmail.com

${ }_{2}^{2}$ Professor do Departamento de Ciências Contábeis da UNEMAT - Campus de Tangará da Serra, e-mail: josyane.costa@hotmail.com
} 
Perfil dos profissionais contábeis dos escritórios de contabilidade que receberam o prêmio Destaque Empresarial na cidade Tangará da Serra - MT

Jucélia Canachiro de Oliveira

Josiane Silva Costa dos Santos Costa

Anualmente a ACITS faz uma pesquisa de opinião pública e premia as melhores empresas do ano denominado Destaque Empresarial. O prêmio destaque empresarial pode ser concorrido tanto pelas empresas associadas e não associadas em apenas um segmento. A empresa deve preencher a ficha no período de inscrição segundo o calendário fornecido pela associação para participar.

Diante do exposto, o objetivo do estudo é identificar o perfil dos profissionais contábeis dos escritórios de contabilidade que receberam o prêmio destaque empresarial na cidade de Tangará da Serra - MT.

Justifica-se este estudo em razão de que existem diversos estudos sobre o perfil dos profissionais contábeis, Serra Talhada - PE (ALVES; MARQUES, 2011), o perfil do profissional contábil (KOUNROUZAN, 2005), perfil do profissional do terceiro milênio (AVI, 1999), profissional contábil no município de Salvador-BH: uma visão inovadora (MOURA; SILVA, 2003), a atuação da mulher contabilista nas organizações contábeis de Florianópolis (COSER, 2005). No entanto, pouco se sabe sobre o perfil dos profissionais contábeis que receberam o prêmio destaque empresarial na cidade de Tangará da Serra - MT.

\section{REFERENCIAL TEÓRICO}

\section{1 - Profissão Contábil}

Figueiredo e Fabri (2000, p20) definem que a função do profissional contábil é:

Executar a contabilidade geral, financeira e gerencial, na área agrícola, bancária, comercial, hospitalar, industrial, imobiliária, pastoril, publica e de seguros, além de todas as outras atividades a ela pertinentes, bem como gerar informações referentes a todos os atos relativos à gestão econômica das organizações.

A profissão contábil está regulamentada pelo decreto-lei nº $9.295 / 46$, de 27 de maio de 1946 e posteriores resoluções complementares. O artigo 25 dessa lei dispõe sobre as atribuições profissionais dos contabilistas:

Art. 25 - são considerados trabalhos técnicos de contabilidade:

a) Organização e execução de serviços de contabilidade em geral;

b) Escrituração dos livros de contabilidade obrigatórios, bem como de todos os necessários no conjunto da organização contábil e levantamento dos respectivos balanços e demonstrações.

c) Perícias judiciais ou extrajudiciais, revisão de balanços e de contas em geral, verificação de haveres, revisão permanente ou periódica de escritas, regulamentações judiciais ou extrajudiciais de avarias grossas ou comuns, assistência aos Conselhos Fiscais das sociedades anônimas e quaisquer outras 
Perfil dos profissionais contábeis dos escritórios de contabilidade que receberam o prêmio Destaque

Empresarial na cidade Tangará da Serra - MT

Jucélia Canachiro de Oliveira

Josiane Silva Costa dos Santos Costa

atribuições de natureza técnica conferidas por lei aos profissionais de contabilidade.

O profissional contábil enfrenta constantes desafios e pressões. Conflitos de demanda, solicitações imprevisíveis e coincidências de prazo limite para o término de serviços são exemplos de situações que ele terá que administrar. Isto requer habilidade e critério para selecionar e assumir prioridades dentro das limitações de tempo e recursos. O profissional contábil tem grande influência para organizar e delegar trabalhos, motivar e desenvolver outras pessoas, e resolver e suportar conflitos, sempre absorver as rápidas mudanças no mundo dos negócios e na tecnologia aplicá-las na organização onde presta serviço. (MARION, 1996)

As funções do profissional contábil são inúmeras. Este possui conhecimentos adquiridos no processo de formação acadêmica e necessita estar se adaptando as inovações constantemente. Ao verdadeiro profissional da contabilidade cabe a função de reciclar as informações, de forma a apresentá-las de maneira apropriada aos diversos usuários, que passarão a ter conhecimento de toda situação patrimonial das organizações, com isso possibilitará ao profissional as condições necessárias de confiança para que possam ser incorporados novos paradigmas, que lhe permita estar sempre bem fundamentado no exercício profissional, permitindo que a sociedade mantenha sobre ele o respeito e procure valorizá-lo como realmente merecer (SILVA 1993).

Figueiredo e Fabri (2000,p.24) destacam que o perfil do profissional contábil deve incluir:

o domínio da linguagem dos negócios, pois é o responsável pelo ambiente de geração de informações fundamentais ao processo decisório/estratégico das organizações. Caracteriza-se como um profissional crítico, ético e lúcido, solidamente capacitado para planejar, organizar, liderar e dirigir as atividades de controle de gerenciamento contábil das empresas.

Marion (2005) destaca que o contador seja o profissional mais bem informado de toda a empresa, pois sua atuação exige que conheça as operações realizadas, faça o seu registro e apresente as informações resultantes do processo contábil na forma de relatórios para administração da empresa, a fim de que esta possa tomar decisões. As decisões tomadas, por sua vez, podem ocasionar retornos positivos ou negativos para a empresa e influenciar quem dela depende. Nessas circunstâncias, o contador assume verdadeiramente uma responsabilidade social. 
Perfil dos profissionais contábeis dos escritórios de contabilidade que receberam o prêmio Destaque Empresarial na cidade Tangará da Serra - MT

Jucélia Canachiro de Oliveira

Josiane Silva Costa dos Santos Costa

O bom profissional contábil deve prestar um serviço diferenciado para seu cliente, auxiliando no gerenciamento das atividades da empresa. É importante que as empresas contábeis invistam em técnica avançada de gestão. Aquelas que possuírem um sistema de gestão eficiente e capaz de fornecer informações úteis aos gestores estarão certamente aptas para garantir sua sobrevivência e continuidade nesse cenário de mudanças e incertezas (SOUSA, 2003).

São inúmeras alternativas para a atuação dos profissionais contábeis: a) nas empresas privadas: contador geral, contador de custos, controller, auditor interno e cargo administrativo; b) em órgãos públicos: contador, fiscal de tributos e tribunal de contas; c) no ensino: professor, pesquisador, escritor e parecerista; e d) atuação independente: auditor independente, consultor, perito contábil, empresário da contabilidade, etc. (MARION, 2005)

O profissional contábil, seja qual for a sua atuação no mercado como: professor, pesquisador, técnico, titular de controle patrimonial, analista de balanço, perito ou consultor deve ocupar o seu verdadeiro lugar, ou seja, o de um agente de transformação da sociedade. É preciso mudar a visão de que o contador é o profissional que possui as suas atividades voltadas exclusivamente para satisfazer às exigências do fisco. (FARI, NOGUEIRA, 2007)

\subsection{O perfil do profissional contábil para o mercado atual}

A era moderna, exige que os contadores estejam aptos para atuar na área dos negócios, e a contabilidade se apresenta com técnica padronizada e universal. Da mesma forma que se busca aprender a língua inglesa como idioma internacional para se comunicar, no mundo dos negócios é imperativo conhecer a Contabilidade (MARION, 2002)

A profissão contábil está passando por significativas mudanças em sua estrutura interna e externa, alterações que ainda não são conhecidas pela grande massa dos profissionais, porém os órgãos estão trabalhando para que essa conscientização seja assimilada de forma global, para que os profissionais ainda fora do novo contexto tenham tempo e formas de reformulação e adaptação às novas necessidades exigidas pelo mercado. (KOUNROUZAN, 2005) 
Perfil dos profissionais contábeis dos escritórios de contabilidade que receberam o prêmio Destaque

Empresarial na cidade Tangará da Serra - MT

Jucélia Canachiro de Oliveira

Josiane Silva Costa dos Santos Costa

De acordo com Moura, Silva (2003), “o perfil do contabilista se modificou, e assim como o conceito emprego, passa por uma profunda e irreversível transformação, que traz consigo novos padrões comportamentais". O fim do curso de graduação, por si só, não garante o sucesso profissional, muito pelo contrário, é o início de uma longa caminhada, que tem como pressuposto básico a educação continuada. Afinal, as empresas estão procurando profissionais cada vez mais especializados, que possuam uma visão generalista e sejam capazes de conectar aos fatos, acontecimentos em várias áreas e ajudar as empresas na execução dos seus objetivos. (CARVALHO, 2002)

O mercado procura um profissional atualizado e dinâmico uma vez que apenas informações não mudam os comportamentos pois é preciso agir com elas. (FRANCO, 1999)

Fari e Nogueira (2007, p.128) reforçam que :

o conhecimento técnico desvinculado da ética pouco serve. $\mathrm{O}$ contador precisa ter um conhecimento amplo da economia, ter facilidade de comunicação e simplicidade na geração de informações para que a sociedade possa compreender. É necessário que leia muito, que tenha a capacidade de analisar, elaborar e interpretar informações gerenciais.

O mercado está requisitando, cada vez mais, profissionais preparados, pois o país tem presenciado a chegada de novas tecnologias despertando no meio empresarial a necessidade de melhorar a sua produtividade e a qualidade dos produtos e serviços. Para não ficar afastado do mercado de trabalho o profissional contábil precisa estar atento às novas ferramentas utilizadas, passando por uma constante reciclagem. (MOURA; SILVA, 2003)

Silva (2003, p.3) afirma que o contador precisa ser aceito como um "comunicador de informações essenciais a tomada de decisões, pois a habilidade em avaliar fatos passados, perceber os presentes e predizer eventos futuros pode ser compreendido como fator preponderante ao sucesso empresarial".

Silva (2003, p. 3) ainda explica que:

[...] o perfil do contador moderno é o de um homem de valor que precisa acumular muitos conhecimentos mas que tem um mercado de trabalho garantido, todavia, que o profissional tenha consciência de que a maior remuneração exige qualidade de trabalho e que esta se consegue com o melhor conhecimento, com estudo, com aplicação, esses profissionais tem que ser tecnicamente inteligentes capacitados. Capaz de compreender e interagir com a política e social, em nível local, regional ou mesmo internacional. 
Perfil dos profissionais contábeis dos escritórios de contabilidade que receberam o prêmio Destaque Empresarial na cidade Tangará da Serra - MT

Jucélia Canachiro de Oliveira

Josiane Silva Costa dos Santos Costa

Fari e Nogueira (2005): consideram que o mercado futuri será mais exigente e complexo e que precisará de contadores especializados em uma atividade contábil específica, e este deverá se um estudante permanente.

O contador tornou-se um consultor profissional confiável, quando aconselhamento é solicitado para ampla gama de assuntos. Para ser bem-sucedido, contudo, os contadores precisam, atualmente, ser treinados de forma diferente. Além dos conhecimentos técnicos essenciais, o contador da atualidade precisa também desenvolver habilidades relativas a comunicação, às relações humanas e à administração, criando um balanceamento adequado entre a formação teórica e a experiência prática. (FRANCO, 1999)

Por fim, cabe salientar que o profissional da contabilidade tem entre outras funções o papel de "resolver enigma do processo administrativo e financeiro, não como obrigado por deliberação, mas como responsáveis pelo arrolamento dos dados que preocupam aos usuários"(SILVA, 2003, p. 3). E ter "confiança de que o executivo se norteie por elementos que favoreça a tomar a melhor decisão, por meio de seus documentos contábeis, bem como os caminhos que devem ser percorridos" (SILVA, 2003).

\section{METODOLOGIA}

Esta pesquisa é de natureza exploratória e descritiva, com abordagem quantitativa.

Primeiramente buscou-se informação na associação comercial e empresarial da cidade de Tangará da Serra (ACITS), a fim de saber quais escritórios de contabilidade que receberam o prêmio destaque empresarial na cidade de Tangará da Serra - MT, onde se teve como resposta 15 escritórios de contabilidade.

Elaborou-se questionários com 10 (dez) questões fechadas, que identificassem o perfil dos profissionais contábeis atuantes nos escritórios de contabilidade.

A pesquisa foi realizada no período do dia 07 ao dia18 de maio do ano de 2012, onde foram distribuídos 109 questionários dos quais retornaram 86.

\section{DISCUSÃO DOS RESULTADOS}


Perfil dos profissionais contábeis dos escritórios de contabilidade que receberam o prêmio Destaque Empresarial na cidade Tangará da Serra - MT

Jucélia Canachiro de Oliveira

Josiane Silva Costa dos Santos Costa

De acordo com o gráfico $01,45 \%$ dos entrevistados são casados e 55\% são solteiros. Estes dados diferem da pesquisa de Alves e Marques 2011, que fizeram um estudo onde $83,33 \%$ são casados, $11,11 \%$ são solteiros e 5,56\% viúvos .

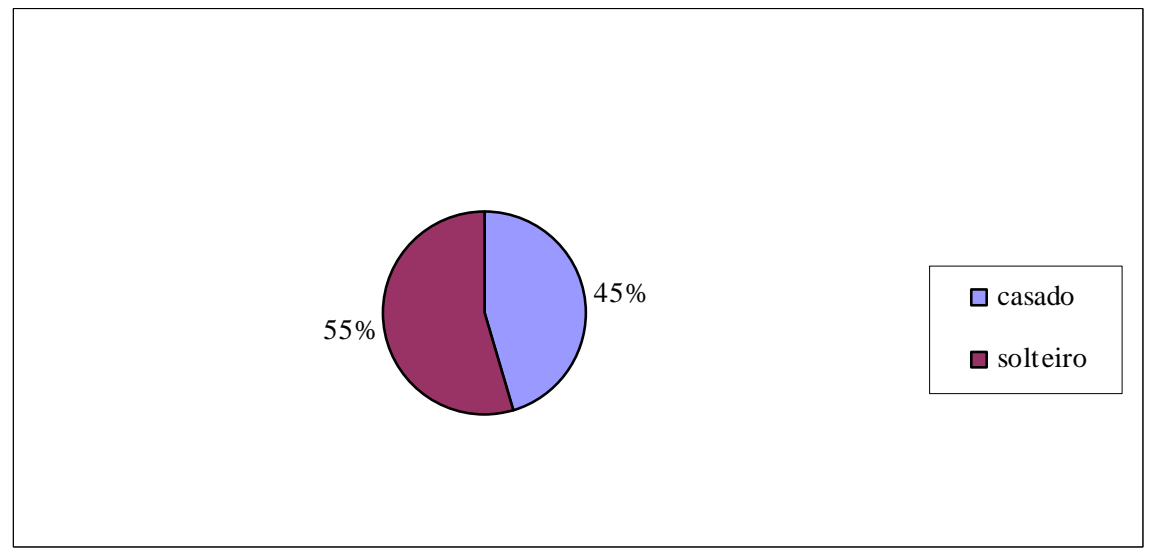

Gráfico 1: Estado civil

Fonte: Pesquisa de campo

Quanto à faixa etária, o estudo revela que, a maioria dos profissionais contábeis entrevistados têm entre 20 e 30 anos (gráfico 2) representando 68\%, de 31 a 40 anos $27 \%$, e $5 \%$ estão entre 41 a 50 anos e as demais opções não tiveram entrevistados que responderam o questionário nesta faixa de idade. Na pesquisa de Alves e Marques 2011 revela que na cidade de Serra Talhada - PE, esses dados divergem pois $44,44 \%$ estão entre 41 e 50 anos e 33,33\% estão entre 51 e 60, e a faixa etária de 20 e 30 representam $11,11 \%$.

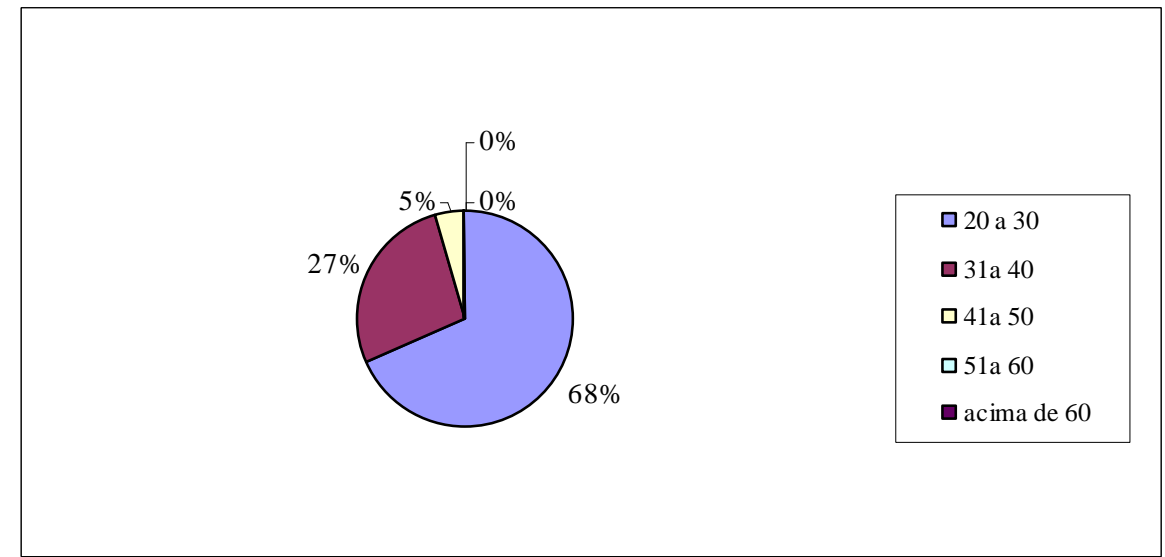

Gráfico 2: Idade dos entrevistados

Fonte: Pesquisa de campo

No que se refere ao sexo dos profissionais contábeis (gráfico 3) $64 \%$ dos entrevistados são do sexo feminino e $36 \%$ do sexo masculino. A pesquisa revela tanto 
Perfil dos profissionais contábeis dos escritórios de contabilidade que receberam o prêmio Destaque Empresarial na cidade Tangará da Serra - MT

Jucélia Canachiro de Oliveira

Josiane Silva Costa dos Santos Costa

quanto na cidade de Tangará da Serra, as mulheres são a maioria, já que na cidade de Serra Talhada - PE, 67\% dos profissionais contábeis são mulheres.

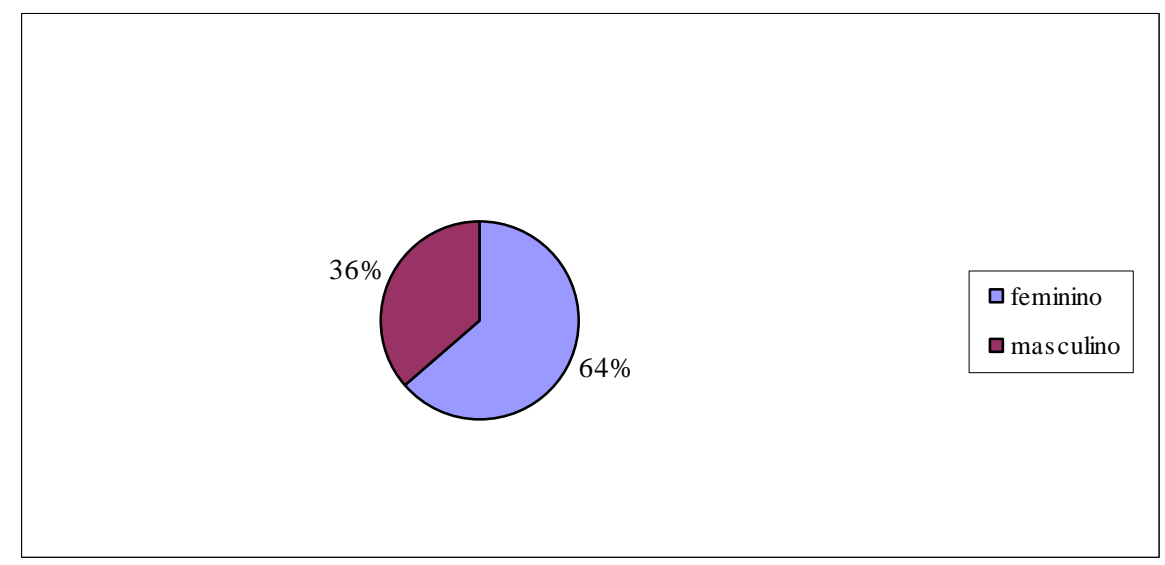

Gráfico3: Sexo dos entrevistados

Fonte: Pesquisa de campo

Quanto a formação escolar, o gráfico 4 indica que 59\% dos entrevistados estão cursando o ensino superior, e $41 \%$ já possuem ensino superior completo sendo que a maioria deles se formaram na Universidade do Estado de Mato Grosso (UNEMAT), já que apenas um dos que responderam o questionário se formou na Universidade do Estado do Paraná. E nenhum dos entrevistados tem curso técnico em contabilidade. Estes dados divergem da pesquisa na cidade de Serra Talhada visto que $61,11 \%$ tem formação do curso superior em Ciências Contábeis e 38,89\% tem o Curso Técnico em Contabilidade. Pode-se observar por esses dados, pois refletem a quantidade de profissionais formados na UNEMAT, que estão atuando na área contábil na cidade de Tangará da Serra - MT.

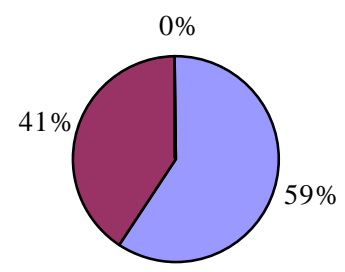

$\square$ superior incompleto

$\square$ superior completo

$\square$ tecnico em contabilidade

Gráfico 4: Nível de formação escolar

Fonte: Pesquisa de campo 
Perfil dos profissionais contábeis dos escritórios de contabilidade que receberam o prêmio Destaque Empresarial na cidade Tangará da Serra - MT

Jucélia Canachiro de Oliveira

Josiane Silva Costa dos Santos Costa

No tocante o tempo de formação acadêmica, verificou-se que $78 \%$ dos participantes estão entre 1 e 5 anos de formação acadêmica e $22 \%$ se formaram a mais de 5 anos conforme gráfico 5. Já na pesquisa Aves e Marques 2011 os entrevistados $27,27 \%$ são formados mais de 5 anos e $72,73 \%$ entre 1 e 5 anos.

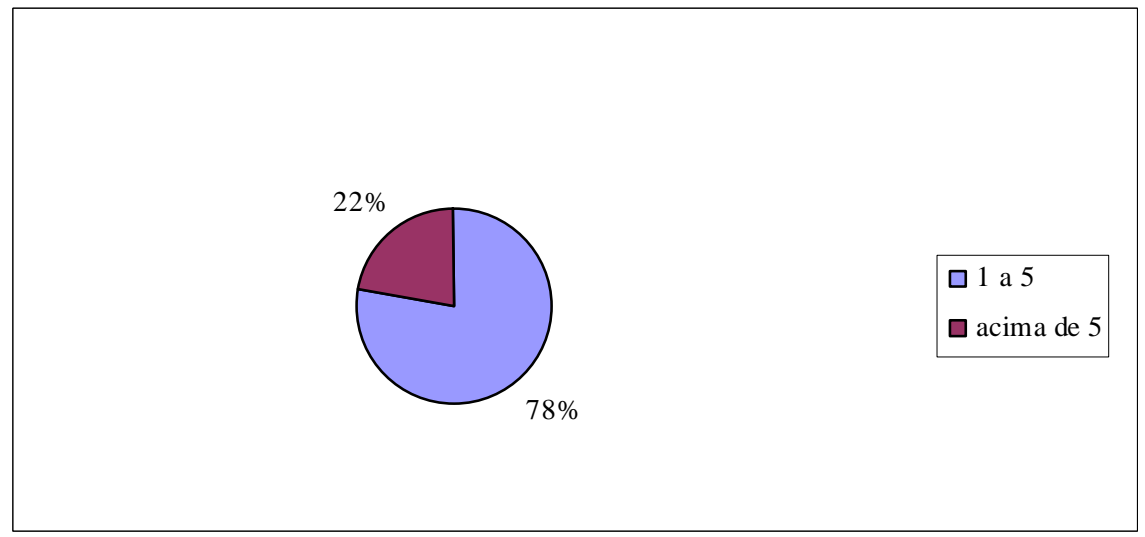

Gráfico 5: Tempo de formação acadêmica Fonte: Pesquisa de campo

A pesquisa também procurou identificar se os profissionais contábeis formados entrevistados possuem registro no Conselho Regional de Contabilidade (CRC), o resultado obtido é exposto no gráfico 6, no qual 35\% responderam sim, e $65 \%$ ainda não possuem o registro no Conselho Regional de Contabilidade (CRC). Dados diverge da pesquisa de (COSER, 2005) onde 72,07\% dos profissionais contábeis possuem registro no CRC na cidade de Florianópolis - SC.

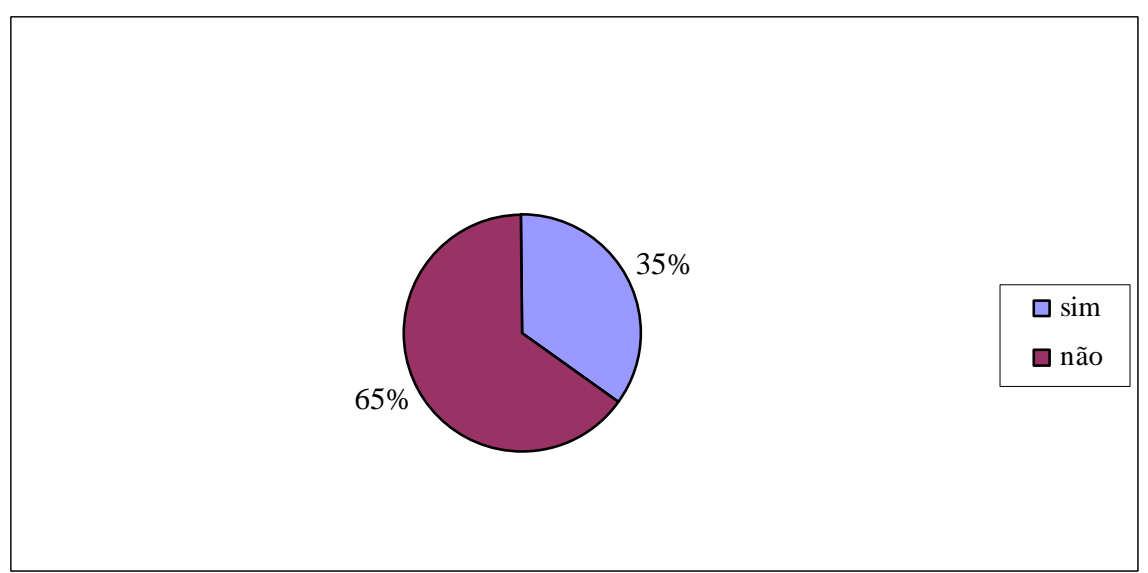

Gráfico 6: Possui registro no Conselho Regional de Contabilidade (CRC) Fonte: Pesquisa de Campo

A Tabela 1 apresenta informações referente aos motivos que levaram os entrevistados à optarem pela profissão contábil, mostrando que ótimo mercado de 
Perfil dos profissionais contábeis dos escritórios de contabilidade que receberam o prêmio Destaque Empresarial na cidade Tangará da Serra - MT

Jucélia Canachiro de Oliveira

Josiane Silva Costa dos Santos Costa

trabalho, é apontado como uma das causas principais da escolha, seguido de surgimento de oportunidades, e logo de finalidade natural com a profissão. Pode-se observar relacionados os dados da pesquisa de Alves e Marques 2011, mostra que a realização pessoal, no qual 25,58\% assinalaram este quesito, e finalidade natural com a profissão aparece em segundo lugar com 18,60\%, a não dependência de emprego fixo com $11,63 \%$.

Tabela 1: Motivos para a escolha da profissão

\begin{tabular}{l|l|l}
\hline Motivos da escolha da profissão & \multicolumn{1}{|c|}{$\begin{array}{c}\text { Esta } \\
\text { pesquisa }\end{array}$} & $\begin{array}{l}\text { Pesquisa de Alves, Marques } \\
\mathbf{( 2 0 1 1})\end{array}$ \\
\hline Realização pessoal & $5 \%$ & $25,58 \%$ \\
\hline Boas perspectivas salariais & $9 \%$ & $4,65 \%$ \\
\hline Relativa independência de outras áreas & & $9,30 \%$ \\
\hline Não depender de emprego fixo & & $11,63 \%$ \\
\hline Ótimo mercado de trabalho & $54 \%$ & $6,98 \%$ \\
\hline Estabilidade da profissão & & $6,98 \%$ \\
\hline Por finalidade natural com a profissão & $9 \%$ & $18,60 \%$ \\
\hline Influencia da família & & $6,98 \%$ \\
\hline Pessoas de sucesso foram modelo & & $2,33 \%$ \\
\hline Surgimento de oportunidades & $23 \%$ & $6,98 \%$ \\
\hline Total & $\mathbf{1 0 0 \%}$ & $\mathbf{1 0 0 \%}$ \\
\hline Fonte Pesquisa de camp &
\end{tabular}

Fonte: Pesquisa de campo

O gráfico 7 representa o nível de satisfação com a profissão contábil e reflete que $90 \%$ disseram estar satisfeitos com a profissão que atuam, enquanto 5\% afirmam que estão plenamente satisfeitos e $5 \%$ expressaram insatisfação com a profissão. Como 90\% disseram satisfeitos apontando uma boa perspectivas quanto ao mercado de trabalho para o futuros contadores. Já na pesquisa de Pugues, 2006 realizada no Rio Grande do Sul as respostas revelam que $87 \%$ dos profissionais contábeis estão satisfeitos com a profissão. Esta situação diverge da pesquisa realizada por Alves e Marques, 2011, onde $61,11 \%$ se dizem satisfeitos em atuar na área contábil. E a pesquisa de (COSER, 2005) 65\%, se dizem satisfeitos com a profissão esses dados revelam boas perspectivas relacionadas a profissão. 
Perfil dos profissionais contábeis dos escritórios de contabilidade que receberam o prêmio Destaque Empresarial na cidade Tangará da Serra - MT

Jucélia Canachiro de Oliveira

Josiane Silva Costa dos Santos Costa

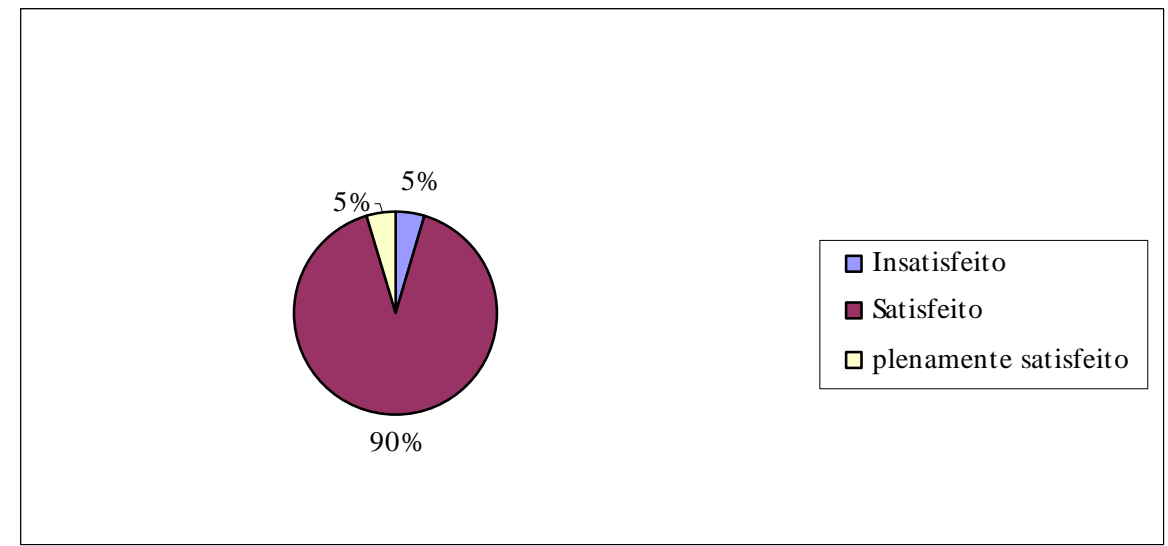

Gráfico 7: Nível de satisfação com a profissão contábil

Fonte: Pesquisa de campo

O volume de trabalho nos escritórios de contabilidade tem levado os profissionais a cumprirem uma carga horária semanal entre 41 e 60 horas de trabalho conforme gráfico 8. Praticamente a mesma quantidade de horas trabalhadas conforme a pesquisa na cidade de Serra Talhada - PE, onde 66,67\% trabalham entre 41 e 60horas semanalmente.

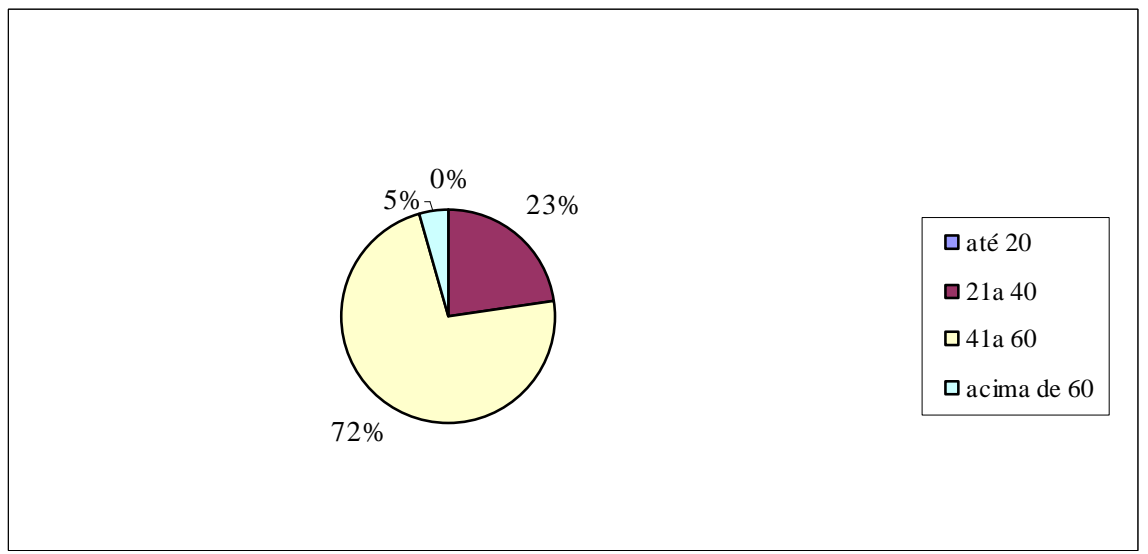

Gráfico 8: Média de horas trabalhadas semanalmente

Fonte: Pesquisa de campo

Nota-se através dos resultados do gráfico 9, que os entrevistados responderam que para se atualizarem profissionalmente a Internet é um dos meios mais procurados para esse fim (50\%), seguido de cursos de aperfeiçoamento $27 \%$, leitura periódica da área (14\%), e educação continuada Conselho Federal de Contabilidade (CFC) (9\%). Analisando quanto a forma de atualização profissional a pesquisa de Alves e Marques 2011, na cidade de Serra Talhada - PE, revela que 14,81\% dos profissionais se atualizam pela internet, $12,96 \%$ educação continuada CFC, 12,04\% cursos de 
Perfil dos profissionais contábeis dos escritórios de contabilidade que receberam o prêmio Destaque Empresarial na cidade Tangará da Serra - MT

Jucélia Canachiro de Oliveira

Josiane Silva Costa dos Santos Costa

aperfeiçoamento. Pode-se avaliar que tal diferença em atualização pelo motivo qual revela a idade dos profissionais pois na cidade de Tangará da a maioria são jovens entre 20 e 30 anos, já na cidade de Serra Talhada - PE, a idade 41 e 50 anos.

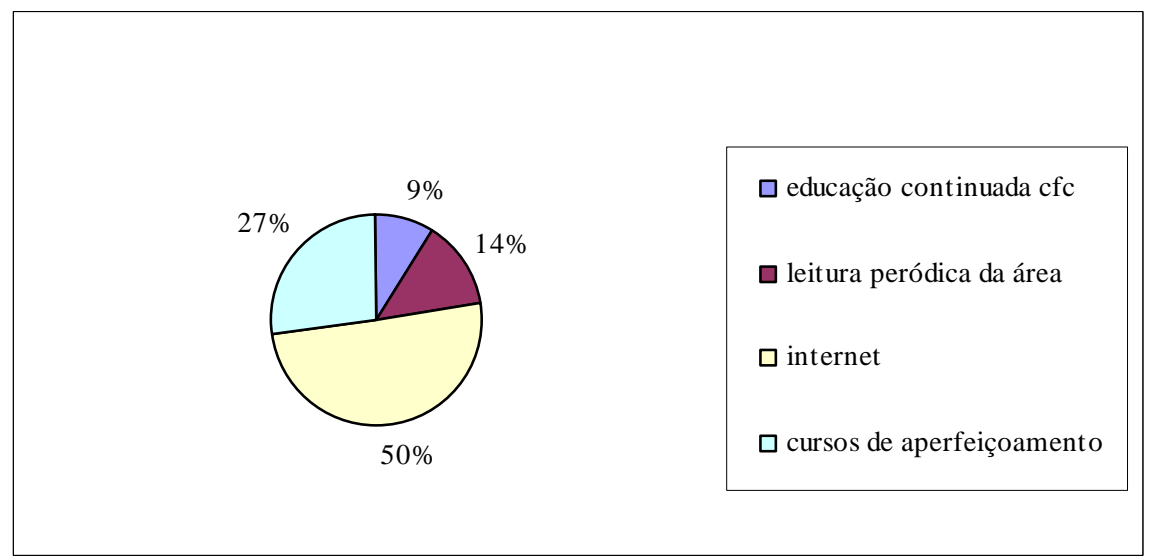

Gráfico 9: Formas de atualizarem profissionalmente

Fonte: Pesquisa de campo

Perguntados quanto às principais dificuldades relacionadas ao exercício da profissão, gráfico 10, os pesquisados apontaram como de maior relevância (67\%) as constantes mudanças na legislação, $23 \%$ baixa remuneração, $5 \%$ legislação complexa e $5 \%$ sendo a falta de recurso de especialização.

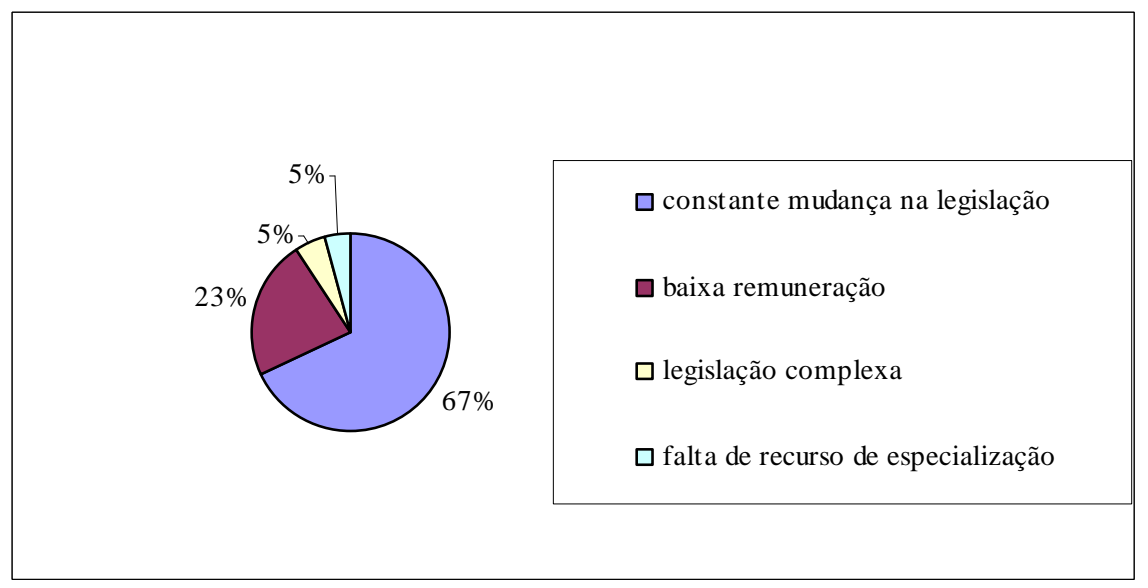

Gráfico 10: Dificuldades relacionadas ao exercício da profissão

Fonte: Pesquisa de campo

O percentual da dificuldade do exercício da profissão na pesquisa de Alves e Marques 2011, encontra-se os seguintes dados, sendo que 18,29\% são as constantes mudanças na legislação. Onde pode-se observar que não é somente na cidade de Tangará da Serra - MT, que as constantes mudanças na legislação é uma das principais dificuldades enfrentadas pelos profissionais contábeis. 
Perfil dos profissionais contábeis dos escritórios de contabilidade que receberam o prêmio Destaque Empresarial na cidade Tangará da Serra - MT

Jucélia Canachiro de Oliveira

Josiane Silva Costa dos Santos Costa

CONCLUSÃO

O objetivo desta pesquisa foi verificar o perfil dos profissionais contábeis dos escritórios de contabilidade que receberam o prêmio destaque empresarial na cidade de Tangará da Serra - MT, tendo por base uma pesquisa de campo reunindo respostas de 86 questionários, em 15 escritórios de contabilidade que compuseram a amostra.

A análise aponta alguns pontos do perfil desses profissionais atuantes nos escritórios de contabilidade, onde entrevistados do sexo feminino foram em números superior ao sexo masculino, a maior parte estão cursando o ensino superior 59\%, e estão entre 20 e 30 anos de idade, e de nível superior completo $41 \%$, e desses profissionais formados 35\% possuem seu registro no Conselho Regional de Contabilidade (CRC).

Os motivos que mais influenciaram os pesquisados para a escolha da profissão foram o ótimo mercado de trabalho, seguido de surgimento de oportunidades. Têm se ainda que os profissionais contábeis dos escritório de contabilidade com destaque empresarial na cidade de Tangará da Serra - MT, tem um bom nível de satisfação com a profissão contábil. E dentre os meios mais utilizados a internet é a ferramenta mais utilizada pelos profissionais contábeis para se atualizarem profissionalmente, e posteriormente com $27 \%$ cursos de aperfeiçoamento, $14 \%$ a leitura periódica da área e 9\% a educação continuada (CFC), as constantes mudanças na legislação é a principal dificuldade encontrada pelos profissionais, no exercício da profissão.

Sugere-se que novas pesquisas sejam feitas a fim de verificar o perfil dos profissionais dos escritórios de contabilidade da Cidade de Tangará da Serra-MT, e se existem diferenças ou semelhanças aqui encontrado, visto que na cidade existem aproximadamente 40 escritórios de contabilidade.

\section{REFERÊNCIAS}

ALVES, José de Souza; MARQUES, Eddie Raoni de Lima. O perfil do profissional contábil da cidade de Serra Talhada - PE. - Revista de Contabilidade e Negócios do Sertão ano 1, Vol. 1, p. 13-21, abr. 2011

Associação comercial empresarial de tangara da serra. Missão, Visão e Valores: Disponível em:< http://www.acits.com.br/> Acesso em: 18 de maio de 2012

AVI, Rosana. O perfil do contador no terceiro milênio. Florianópolis: UFSC, 1999. Trabalho de Conclusão de Curso - Departamento de Ciências Contábeis, 
Perfil dos profissionais contábeis dos escritórios de contabilidade que receberam o prêmio Destaque Empresarial na cidade Tangará da Serra - MT Jucélia Canachiro de Oliveira Josiane Silva Costa dos Santos Costa

Universidade Federal de Santa Catarina, 19 jun. 1999. Disponível em:<http://www.infinitaweb.com.br/albruni/artigos/a0703_IntCustos_Prof_Contabil.pdf $>$ acesso em: 26 de abril 2012

CARVALHO, Joana D’Arc Silva Galvão de. O perfil profissional do contador ingresso no mercado de trabalho no município de Salvador-Ba de 1991 a 2000. Salvador: FVC, 2002. Dissertação (Mestrado em Contabilidade), Centro de PósGraduação e Pesquisa Visconde de Cairú - CEPPEV, Fundação Visconde de Cairú, 2002.

CONSELHO FEDERAL DE CONTABILIDADE. Legislação da Profissão Contábil. Brasília: CFC. 2003.

COSER, Clair. A Atuação da Mulher Contabilista nas organizações Contábeis de Florianópolis:UFSC,2005, Trabalho de Conclusão de Curso - Departamento de Ciências Contábeis, Universidade de Santa Catarina, 29 de julho de 2005. Disponível em: <http://www. http://tcc.bu.ufsc.br/Contabeis294519.PDF>Acesso em:18 de maio 2012

FARI, Murilo Arthur, NOGUEIRA, Valdir. Perfil do profissional contábil: relações entre formação e atuação no mercado de Trabalho. Artigo publicado Perspectivas Contemporâneas, Campo Mourão, v.2, p. 117-131, jan/jun.2007.

FIGUEIREDO, Sandra; FABRI, Pedro Ernesto. Gestão de Empresas Contábeis. São Paulo:Atlas, 2000

FRANCO,S.Criando o próprio futuro: O mercado de trabalho na era da competitividade total. São Paulo: Ática, 1999.

KOUNROUZAN, Márcia Covaciuc. O perfil do profissional contábil. Disponível em: <http://www.oswaldocruz.br/download/artigos/social17.pdf.> acesso em: 24 de abril 2012

MARION, José Carlos. Contabilidade empresarial. 9. Ed. São Paulo: Editora Atlas, 2002

MARION, José Carlos. Contabilidade Empresarial. 11. Ed. - São Paulo: Atlas, 2005.

MARION, José Carlos. O Ensino da Contabilidade. São Paulo: Atlas, 1996.

MOURA, Iraildo José Lopes de; SILVA, Marcus Vinicius Peixoto; Profissional Contábil no Município de Salvador-Bahia: uma visão inovadora. Bahia 2003.

Disponível em: <http://iraildojose.sites.uol.com.br/monografia.html> acesso em: 20 de maio de 2012

PUGUES, Laurise Martha. O Perfil Profissional de Egressos dos Cursos de Ciências Contábeis no Rio Grande do Sul. Disponível em:<http://www.congressocfc.org.br/hotsite/trabalhos_1/503.pdf> acesso em: 17 de maio de2012 
RIBEIRO, Magno Alves, TORRES, Ariel Lopes, ROCHA, Margarida Alves. Manual para elaboração e apresentação de monografias. 1 ed. Tangará da Serra-MT:

Unemat: 2006.

SILVA, Edgard de Lima. A importância do Profissional de Contabilidade no desempenho da Organização. In: Encontro Nordestino De Contabilidade, I. Olinda, PE, 27-30 out. 1993. Brasília, CFC, 1993. p. 285-6.

SILVA, Tânia Moura. Currículo Flexível: Evolução e Competência.Revista Brasileira de Contabilidade do CFC, edição ano XXIX - No. 121-Janeiro/Fevereiro 2000paginas 23 a 27.

SILVA, Antônio Carlos Ribeiro. Metodologia da pesquisa aplicada à contabilidade: orientações de estudos, projetos, relatórios, monografias, dissertações, teses. São Paulo: Atlas, 2003.

SOUSA, Tarcita Cabral Ghizoni. Modelo de Gestão por atividades para empresas contábeis. Dissertação de Mestrado. UFSC. 2003 